\title{
Producción de harina de papa para puré instantáneo
}

\author{
J. Alonso, K. Z. García-Jarquín, K. González-Lindo, M. Benavente* \\ Facultad de Ingeniería Química, Universidad Nacional de Ingeniería (UNI) \\ Avenida Universitaria, PO Box 5595, Managua, Nicaragua \\ (recibido/received: 30-Oct-2014; aceptado/accepted: 19-Dic-2014)
}

\begin{abstract}
RESUMEN
Este estudio se basó en la producción de harina de papa para puré instantáneo, utilizando las variedades de papas nacionales Provento y Granola. Para ello, se determinó el porcentaje de humedad de las papas, resultando la variedad Granola con el menor rango de humedad y mayor contenido de materia seca. Adicionalmente, se estudió la efectividad de los tratamientos fisicoquímicos (temperatura, reducción de oxígeno atmosférico y uso de reactivos químicos) para la inhibición de la enzima Polifenoloxidasa en el tubérculo. Los resultados mostraron que los tratamientos térmicos, sin uso de agentes químicos, fueron la mejor opción para la inhibición enzimática. La determinación de las curvas de secado de la pasta de papa, con tratamiento previo, se llevó a cabo en un secador de túnel a $60{ }^{\circ} \mathrm{C}$ y una velocidad de aire de $0.2 \mathrm{~m} / \mathrm{s}$. Los pre-tratamientos incluyeron escaldado, cocción y el uso de ácido ascórbico y metabisulfito de sodio. Los resultados indicaron que con la aplicación del tratamiento térmico al tubérculo fue suficiente para evitar el pardeamiento enzimático y además, se logra un menor tiempo de secado. Los datos experimentales fueron evaluados usando el modelo de Midilli observándose un buen ajuste con un $\mathrm{R}^{2}>0.99$. Además, se comprobó que el método más óptimo para la producción de harina de papa involucra las siguientes etapas: cocción, enfriamiento y reducción de tamaño en seco. Esto garantiza una harina, que según los resultados de poder de hinchamiento, solubilidad en agua y absorción de agua, alcanza las características de almidón instantáneo lo cual favorece la formación de un puré de manera rápida. Los rendimientos en la producción de harina oscilan entre 12.55-14.09\% para la Granola y entre $11.18-15.58 \%$ para la provento en base húmeda.
\end{abstract}

Palabras clave: Harina de papa; Inhibición enzimática; Papa granola y provento; Curvas de secado; modelo de Midilli

\begin{abstract}
In this study, potatoes flour for instant purée was produced using national potato varieties Provento and Granola. For this, the moisture content of potatoes was determined; the results showed that the Granola variety has lower moisture range and higher dry matter. Also, the effectiveness of physicochemical treatments (temperature, reduction of atmospheric oxygen and the use of chemical reagents) was studied for inhibition of polyphenol oxidase enzyme in the potatoes. The results showed that heat treatments, without the use of chemical agents, were the best choice for enzyme inhibition. The determination of the drying curves for potato paste, with pretreatment, was conducted in a drying tunnel at $60^{\circ} \mathrm{C}$ and an air velocity of $0.2 \mathrm{~m} / \mathrm{s}$. The pre-treatments include blanching, cooking, and the use of ascorbic acid and sodium metabisulfite. The results indicated that the applying heat treatment to potatoes was sufficient to prevent enzymatic browning and also, a lower drying time is achieved. Experimental data were evaluated using Midilli model, showing a good fit with an $\mathrm{R}^{2}>0.99$. Also, it was found that the optimal method for the preparation of potato flour involves the following steps: cooking, cooling and dry size reduction. This ensures that the flour, according to the results of swelling power, solubility in water and water absorption, reaches instant starch characteristics favoring the formation of a puree quickly. Yields in flour production range from 12.55 to $14.09 \%$ for Granola and between 11.18 to $15.58 \%$ for Provento wet basis.
\end{abstract}

Keywords: Potato flour; Enzyme inhibition; Granola and provento potatoes; Drying curves; Midilli model

\footnotetext{
*Autor para la correspondencia. Tel.: +505 22781463.

Correo electrónico: martha.benavente@fiq.uni.edu.ni (M. Benavente).
} 


\section{Introducción}

La papa o patata (Solanum tuberosum) es una planta de la familia solanáceas y es cultivada por su tubérculo comestible en casi todo el mundo. En Nicaragua la producción de papas frescas es deficitaria considerando la demanda global que existe en relación a este tubérculo, lo que significa que la compra de papa corresponde a importaciones de países Centroamericanos como Costa Rica. Sin embargo, a pesar de las dificultades los productores nacionales han aumentado los rendimientos de producción, lo que ha venido a dinamizar este mercado a nivel nacional. Pero la gran cantidad de papa importada les provoca cuantiosas pérdidas del tubérculo, lo que ha generado buscar otras alternativas para el uso de la papa.

Por lo anterior, la Organización de las Naciones Unidas para la Alimentación y la Agricultura (FAO, por sus siglas en inglés), ha desarrollado proyectos y acciones que han fortalecido la producción agropecuaria, exportaciones agrícolas para algunos rubros y en especial la seguridad alimentaria a beneficio de los sectores más pobres de Nicaragua (FAO, 2010). Uno de estos proyectos está encaminado a aprovechar el alto valor nutritivo de la papa, para ello la FAO ha incidido en el fortalecimiento de las capacidades de acopio, almacenamiento y comercialización de los productores organizados, en las cooperativas y asociaciones adscritas a la Comisión Nacional de Productores de Papa de Nicaragua (CONAPAPA), y ha venido a sugerir el desarrollo de productos novedosos elaborados a partir de la papa. Entre los cuales se encuentran: potaje para niños, jugos y harina de papa.

En América Latina países como Perú y Argentina son los que han realizado esfuerzos para industrializarla y crear un valor agregado a la papa. En Nicaragua, no existe ninguna documentación de empresa o cooperativa que haya desarrollado la producción de harina de papa a escala industrial o semi-industrial. Sin embargo, en la Facultad de Ingeniería Química (FIQ) se llevó a cabo una tesina acerca de la "Elaboración de Harina de Papa", cuyo objetivo se centró en determinar un proceso adecuado para producir harina de papa y realizar pruebas de humedad a la harina obtenida (Gallegos y Umaña, 2010).

Con este trabajo se pretende obtener harina a partir de las variedades de papa Granola y Provento, con la finalidad de elaborar puré; así como su utilización en la mejora de los rendimientos en la producción de pan a base de trigo, convirtiéndola en un producto versátil. Para la obtención de la harina, se tomaron en cuenta diversos factores como: la humedad contenida en las variedades de papa, métodos de inhibición y secado del tubérculo. Así también, se consideró la caracterización fisicoquímicas de la harina obtenida: contenido de humedad, cenizas, proteínas, grasa, fibra, carbohidratos, índice de solubilidad en agua (ISA), adsorción en agua (IAA) y poder de hinchamiento (PH); y la aplicación de un análisis sensorial, a través de una prueba hedónica para conocer el grado de aceptabilidad tanto de la harina como del puré.

\section{Material y Métodos}

\subsection{Material}

El trabajo fue realizado en el Recinto Universitario "Simón Bolívar" (RUSB), de la UNI, en los Laboratorios de Alimentos, Operaciones Unitarias, Secado y Química. Las papas variedad Provento y Granola fueron suministradas por productores de los departamentos de Estelí, Matagalpa y Jinotega. Los reactivos utilizados (ácido cítrico, ácido ascórbico y metabisulfito de sodio) fueron de grado alimenticio.

\subsection{Determinación de humedad de papas nacionales}

Para determinar la cantidad de humedad de las variedades de papa Provento y Granola se utilizó el método de secado en termobalanza (Kirk et al., 1996) en una termobalanza Sartorius, MA 150.

Primeramente, las papas se cortaron en cuatro cuadrantes extrayendo tejido vegetal de cada uno de ellas. Los cortes no excedieron de 0.15 $\mathrm{mm}$ a $0.25 \mathrm{~mm}$ de grosor y de 1 a $15 \mathrm{~mm}$ de 
largo para que la balanza secara el tejido lo más uniformemente posible.

El tejido vegetal se introdujo en la termobalanza, para que se llevara a cabo el proceso de deshidratación de la materia húmeda a una temperatura de $105^{\circ} \mathrm{C}$.

Es muy importante mantener constante la base de cálculo (peso de la muestra) para evitar que sea un factor que influya en la varianza de los resultados. Para cada variedad se repitió tres veces el mismo procedimiento.

\subsection{Inhibición enzimática de la papa}

El pardeamiento enzimático en los alimentos es un cambio indeseable porque reduce el grado de aceptación de los productos. La polifenoloxidasa (PPO), también conocida por catecol oxidasa, es una metaloenzima, responsable de las reacciones de pardeamiento enzimático en frutas y verduras, así como de la modificación de sus propiedades sensoriales y nutricionales (Guerrero-Eraso, 2009).

La transformación enzimática en los vegetales puede ser controlado a través del uso de métodos físicos y químicos. Los métodos físicos incluyen la reducción de temperatura y/o oxígeno, uso de empaque en atmósferas modificadas y tratamiento con irradiación a altas presiones. Los métodos químicos utilizan compuestos que inhiben la enzima, eliminan sus sustratos (oxígeno $\mathrm{y}$ fenoles) o funcionan como un sustrato preferido (Science, Technology and Market, 2002).

Es por ello que este estudio (con las variedades de papa Granola y Provento) se llevó a cabo con y sin tratamiento fisicoquímico, para comprobar si los métodos aplicados inhiben o no a la enzima polifenoloxidasa (PPO) presente en la papa.

Primeramente las papas fueron debidamente lavadas y retiradas las cáscaras; luego, fueron cortadas en cubos con dimensiones de $15 \mathrm{~mm}$ de largo y $5 \mathrm{~mm}$ de ancho. Posteriormente, algunas de las papas cortadas fueron sometidas a las siguientes condiciones de trabajo:
- No escaldadas y sumergidas en agua a temperatura ambiente.

- No escaldadas y sumergidas en agua a $25{ }^{\circ} \mathrm{C}$ (reducción de oxigeno atmosférico)

- Escaldadas a $85{ }^{\circ} \mathrm{C}$ durante 3 minutos y sumergidas en agua a $25{ }^{\circ} \mathrm{C}$ (reducción de oxigeno atmosférico).

- Escaldadas a $85{ }^{\circ} \mathrm{C}$ durante 3 minutos y sumergidas en agua fría a $10{ }^{\circ} \mathrm{C}$ con presencia de diferentes inhibidores enzimáticos (ácido cítrico, ácido ascórbico y metabisulfito de sodio) por separado.

La enzima de las papas fue extraída en cada caso mediante la operación mecánica de una licuadora en un medio acuoso de buffer de fosfato en frío y filtrada con el fin de dejar pasar sólo el líquido, evitando el ingreso de tejido vegetal con dimensiones de tamaño aún mayores a las deseadas. Cabe destacar que el buffer de fosfato como disolución amortiguadora del $\mathrm{pH}$ permite que exista una reducción de tamaño del tubérculo hasta convertirlo en una especie de pasta sin modificar el perfil de expresión y funcionamiento celular, ya que es un vehículo neutro para las células (Wikipedia, 2014). La extracción de la enzima fue realizada cada 20 minutos hasta alcanzar un lapso de 1 hora y 20 minutos, para evidenciar el comportamiento oxidativo en cada caso.

Para controlar la activación enzimática se midió la absorbancia por espectrofotometría ultravioleta-visible; ya que ésta es proporcional a la concentración de la enzima PPO en la muestra. La lectura de absorbancia se realizó a una longitud de onda de $420 \mathrm{~nm}$ a intervalos de 15 segundos durante 2 minutos periodo en el cual la enzima extraída se encontraba en medio de catecol diluido en buffer de fosfato ( $\mathrm{pH}$ 6.5) para simular la reacción de oxidación (actividad de catecolasa), que tiene lugar cuando un grupo o-difenol como el catecol es convertido para producir la correspondiente benzoquinona. (Wikipedia, 2014).

\subsection{Curvas de secado}

El secado de las muestras de papas se llevó a cabo en un secador de túnel. Para este estudio, se trabajó con las variedades de papa: Provento y 
Granola, y dos inhibidores enzimáticos: ácido ascórbico y metabisulfito de sodio. Las muestras fueron preparadas de acuerdo a los dos métodos descritos subsiguientemente. Dado que se realizó una réplica para cada tipo de prueba, se obtuvieron en total de 16 curvas experimentales de secado (8 para cada método experimental).

a) Método 1: Tratamiento térmico + inhibidor enzimático

Este método consiste en inactivar la enzima de la papa primeramente con un escaldado de 2 minutos a $85{ }^{\circ} \mathrm{C}$, colocando enseguida la muestra en contacto con un inhibidor enzimático (metabisulfito de sodio o ácido ascórbico) por 45 minutos a $10{ }^{\circ} \mathrm{C}$. Luego, la muestra se tritura en una licuadora y se coloca en el porta-muestras para proceder a secarla en el secador de túnel.

b) Método 2: Tratamiento térmico: escaldado o cocción

Los trozos de papa, se escaldaron por un tiempo de 2 minutos a $85^{\circ} \mathrm{C}$, luego se enfría y se tritura la muestra en una licuadora para luego colocarla en el porta-muestras del secador de túnel.

La cocción se realiza de igual manera que el escaldado, solo que ahora los trozos de papa se ponen en agua hirviendo por 20 minutos hasta que la papa este totalmente blanda, se enfría y se tritura la muestra con un mortero para luego pasar a la etapa de secado.

Para la realización del secado de la pasta de cada una de las muestras (con un peso uniforme), éstas se situaron en un porta-muestras de porcelana cubriendo por completo la base del recipiente, de tal manera que la corriente de aire estuviera en contacto con la superficie superior de la pasta de papa. El porta-muestras utilizado posee una dimensión de $70 \times 45 \mathrm{~mm}$ y $5 \mathrm{~mm}$ de espesor.

La pérdida en peso de la muestra se determinó pesando la muestra en una balanza analítica, registrando el dato cada cierto intervalo de tiempo sin interrumpir la operación, terminando el experimento hasta que el peso fuera constante.
El secado se realizó a una velocidad de aire de $0.2 \mathrm{~m} / \mathrm{s}$ y a una temperatura de $60^{\circ} \mathrm{C}$.

Con los resultados de los pesos registrados, se calcula el contenido de humedad a un tiempo $t$ con la siguiente Ecuación (1):

$$
X_{t}=\frac{W-W_{s}}{W_{s}}
$$

donde $X_{\mathrm{t}}$ es el contenido de humedad ( $\mathrm{g}$ de agua/g de sólido seco); $W$ es el peso del solido húmedo en $\mathrm{g}$ totales de agua más sólido seco y $W_{s}$ es el peso del solido seco $(\mathrm{g})$.

Para evaluar los datos experimentales obtenidos para cada variedad de papa, se aplicó el modelo propuesto por Midilli et al. (2002):

$M R=a \exp \left(-k t^{n}\right)+b t$

donde $M R$ es la relación de humedad en base seca (adimensional); $a, b, n$ y $k$ son los parámetros de secado para el modelo; siendo:

$$
M R=\frac{M_{d}-M_{e}}{M_{0}-M_{e}}
$$

donde $M_{d}, M_{e}$ y $M_{0}$ son el contenido de humedad a un tiempo $t$, en el equilibrio e inicial, respectivamente ( $\mathrm{kg}$ agua $/ \mathrm{kg}$ materia seca) (Taheri-Garavand et al., 2011). Ya que los valores de $M_{e}$ relativamente pequeños en comparación con $M_{d}$ o $M_{0}$, el error involucrado en la simplificación es despreciable, entonces la relación de humedad se calcula como:

$M R=\frac{M_{d}}{M_{0}}$

\subsection{Producción de harina}

Las etapas para la producción de harina de papa (Provento y Granola) fueron establecidas bajo criterios de pasos sencillos y con base científica para obtener un producto con el menor procesamiento posible y sin el uso de preservantes químicos. 
Para la producción del producto se llevaron a cabo dos métodos diferentes: (i) un método basado en las referencias bibliográficas obtenidas en la primera fase del estudio, el cual aduce que mejora la vida útil de la harina y (ii) un método que disminuye las etapas de exposición de la papa en agua y conlleva a obtener una harina de mejor calidad.

Las etapas se describen a continuación:

- Recepción, selección y lavado.

- Pesado, pelado y corte.

- Primer método: escaldado a $85^{\circ} \mathrm{C}$ por $3 \mathrm{~min}$, enfriamiento y molienda.

- Segundo método: cocción a $90-95{ }^{\circ} \mathrm{C}$ por 20 min, enfriamiento y maceración.

- Secado a $50{ }^{\circ} \mathrm{C}$

- Trituración y tamizado $(<0.22 \mathrm{~mm})$.

\subsection{Caracterización fisicoquímica del producto}

Para determinar la calidad de la harina a partir de las papas variedad Provento y Granola, el producto fue sometido a un análisis fisicoquímico (ver Tabla 1). La determinación del aporte nutricional y energético de la harina fue mediante un análisis proximal con los métodos oficiales de la A.O.A.C.

Tabla 1 Métodos analíticos utilizados para la caracterización de la harina de papa.

\begin{tabular}{ccc}
\hline Análisis & Método & No. muestras \\
\hline \%Humedad & Kirk et al. & 6 \\
\%Ceniza & Directo & 6 \\
\%Grasa & Soxhlet & 2 \\
\%Proteína & Kjeldahl & 2 \\
\%Fibra & Gravimétrico & 2 \\
\hline IAA & Anderson $e t$ & \\
ISA\% & $a l$. & 4 \\
PH & & \\
\hline
\end{tabular}

\section{Resultados y Discusión}

\subsection{Determinación de la humedad (\%)}

Los resultados del porcentaje de humedad de las papas variedad provento y granola se presentan en la Tabla 2. Se observa que la papa variedad granola tiene un \%Humedad promedio de los
$82 \%$, siendo menor que el \%Humedad de la papa variedad provento $(85.81 \%)$. De estos resultados podemos afirmar que la variedad de papa granola sería la más óptima para producir harina; mientras que la papa provento requeriría mayor tiempo de secado por presentar mayores porcentajes de humedad. En comparación a la variedades de papa encontradas en las zonas andinas (que poseen entre $72-75 \%$ de humedad), las variedades nacionales provento y granola tienen entre 8-11\% más humedad (FAO, 2008).

Tabla 2 Porcentaje de Humedad de dos variedades de papa.

\begin{tabular}{ccc}
\hline \multirow{2}{*}{ No. } & \multicolumn{2}{c}{ Humedad (\%) } \\
\cline { 2 - 3 } & Provento & Granola \\
\hline 1 & 82.34 & 80.79 \\
2 & 86.50 & 81.27 \\
3 & 88.60 & 83.90 \\
\hline Promedio & 85.81 & 82.00 \\
\hline
\end{tabular}

Estos resultados también muestran que las variedades granola y provento alcanzan el $18 \%$ y $14.2 \%$ de materia seca, respectivamente; es decir, $6 \%$ menos de lo establecido para producir harina de este tipo, que es del $24 \%$. Esto indica que con estas variedades de papa nacional se puede producir harina pero con menores rendimientos de obtención del producto en comparación con empresas internacionales que ocupan otras variedades con mayor contendido de materia seca y menor humedad (Egúsquiza, 2000).

\subsection{Inhibición enzimática de la papa}

Las PPOs catalizan una reacción que transforma el o-difenoles en o-quinonas, las cuales son muy reactivas y atacan a una gran variedad de componentes celulares, favoreciendo la formación de polímeros negro-marrón. Estos polímeros son los responsables del oscurecimiento de tejidos vegetales cuando se dañan físicamente. Esto se observa fácilmente en las papas, que tienen altos niveles de PPOs (Hernández-Valdez, 2009).

Para estudiar la inhibición enzimática que se consigue con las variedades de papa Granola y Provento, se separaron tres lotes de papas: al 
primer lote no se le aplicó ningún tipo de tratamiento fisicoquímico (A); al segundo lote se le aplicó tratamientos físicos: cambios de temperatura y reducción de oxígeno atmosférico (B y C) y al tercer lote se le aplicó tratamientos físicos-químicos: cambios de temperatura, reducción del oxígeno atmosférico y uso de inhibidores enzimáticos (D, E y F). En el gráfico de absorbancia en función del tiempo (min) de la Fig. 1(a) se muestran los resultados obtenidos para la variedad Granola y en la Fig. 1(b) los resultados para la variedad Provento.

En la Fig. 1(a) se observa que la línea A muestra un aumento gradual en los niveles de absorbancia con respecto al tiempo, alcanzando a los $80 \mathrm{~min}$ un valor máximo (0.967). Este comportamiento se debe a que, al no haber ningún tratamiento, las enzimas PPO presentes en la muestras interactuaran con el catecol, que actúa como sustrato, provocando la reacción de pardeamiento y el incremento gradual de la coloración negra o gris en las muestra.

Por su parte en la línea B, aunque se observa un descenso en los niveles de absorbancia con respecto a la línea $\mathrm{A}$, siempre hay un incremento de la absorbancia con respecto al tiempo. En este tratamiento, el tubérculo fue expuesto en un medio acuoso a temperatura ambiente $\left(25{ }^{\circ} \mathrm{C}\right)$ con el objetivo de evitar que los compuestos fenólicos entraran en contacto con el oxígeno atmosférico, siendo éste uno de los factores causantes de la activación de las enzimas.

Este resultado indica que el método de inmersión en agua, no es lo suficientemente efectivo para inhibir la acción de las enzimas PPOs en las muestras.

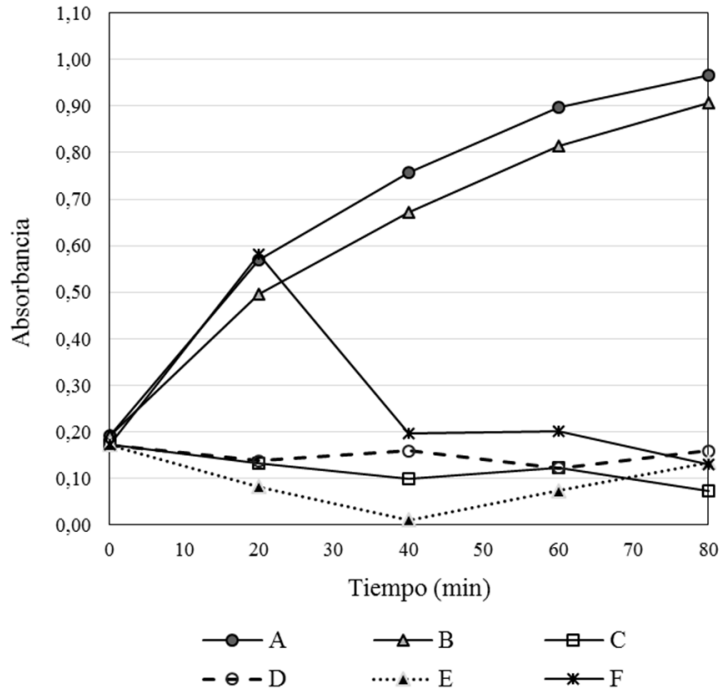

(a) Papa variedad Granola

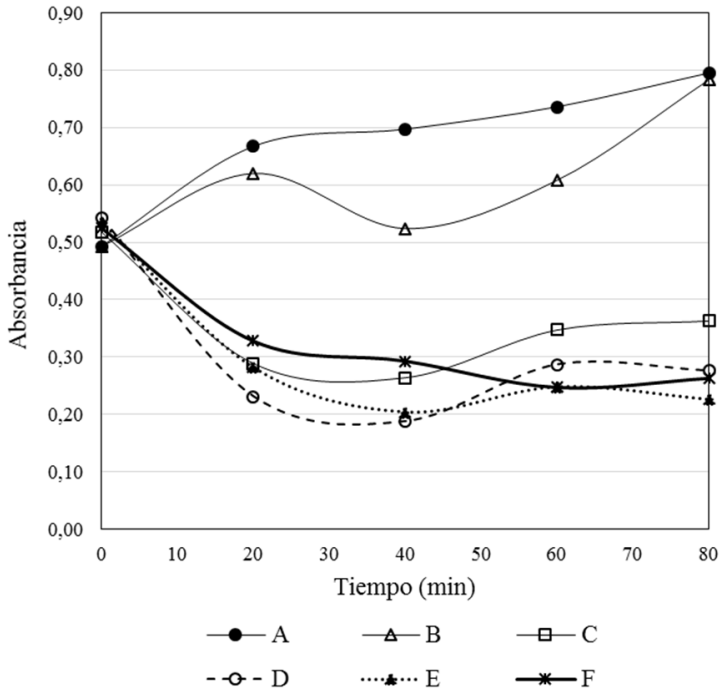

(b) Papa variedad Provento

Fig. 1 Comportamiento de la Polifenoloxidasa (PPO) en la papa: A (sin ningún tratamiento), B (reducción de oxígeno atmosférico), C (escaldada + reducción de oxígeno atmosférico), D (escaldada+ reducción de oxígeno atmosférico+ metabisulfito de sodio), E (escaldada+ reducción de oxígeno atmosférico+ ácido ascórbico) y F (escaldada+ reducción de oxígeno atmosférico + ácido cítrico). 
La línea $\mathrm{C}$ representa a la papa que fue escaldada a $85{ }^{\circ} \mathrm{C}$ e inmediatamente expuesta a un choque térmico de agua fría a $5{ }^{\circ} \mathrm{C}$ (tratamiento físico). En el gráfico se observa que la línea $\mathrm{C}$ decrece en el tiempo; es decir, a mayor tiempo de contacto con el agua o disminución de la temperatura interna del tubérculo, los niveles de absorbancia bajan indicando la baja interacción que tienen las enzimas PPOs con el sustrato catecol. Como se sabe, el objetivo principal del escaldado es la desnaturalización de enzimas, responsables del pardeamiento y de la alteración de aromas. Asociado este método con la baja temperatura y la reducción de oxígeno, conducen a que se obtenga una baja absorbancia en el tiempo (entre 0.07 y 0.17 ).

La velocidad de las reacciones enzimáticas aumenta por lo general con la temperatura, dentro del intervalo en que la enzima es estable y activa. Si se disminuye la temperatura de los alimentos, la velocidad de reacción también lo hace, siendo nula únicamente cuando se alcanza el cero absoluto. De acuerdo con esto, a bajas temperaturas se reduce pero nunca se detiene la actividad enzimática; por consiguiente, un producto puede deteriorarse por vía enzimática durante la congelación por largos periodos, debido a que la actividad es lenta pero existe.

El efecto de la disminución de temperatura, de los sustratos fenólicos y de oxígeno en el proceso de inhibición enzimática se demuestran en las líneas D, E y F; las cuales representan las absorbancias registradas en las papas que fueron tratadas con inhibidores enzimáticos (reactivos químicos) más un tratamiento físico. Según Hernández (2009), este tratamiento es necesario para que no exista un cambio de valencia de los iones cobre $\left(\mathrm{de} \mathrm{Cu}^{2+}\right.$ a $\left.\mathrm{Cu}^{+}\right)$presentes en la metaloenzima; así como también, se evita la formación de un complejo con enlace $\mathrm{O}-\mathrm{O}$ bien polarizado que produce la hidroxilación a odifenilo (ver Fig. 2).

Los resultados de las pruebas experimentales indican que los agentes reductores como el metabisulfito de sodio (línea D) tienen un comportamiento irregular (la absorbancia varía entre 0.12 y 0.17 ) con respecto a la inhibición de la PPO, ya que se oxidan durante la reacción. Esto significa que la protección que confiere este reactivo es únicamente temporal, por ello que en la Fig. 1(a) se observa que la línea D presenta un comportamiento creciente con respecto a la línea $\mathrm{C}$, indicando un aumento en los niveles de absorbancia con respecto al tiempo, recomendándose que la exposición del tubérculo no supere los $40 \mathrm{~min}$.

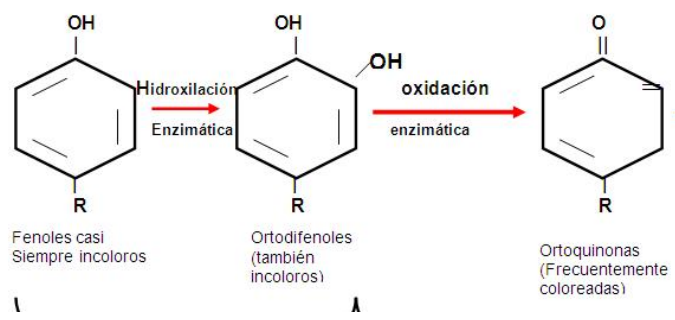

Fig. 2 Reacción de hidroxilación y oxidación enzimática que provoca la formación de compuestos coloreados en los vegetales (UNAD, 2014).

Otro reductor utilizado fue el ácido ascórbico (línea E) que a los 40 minutos registra el valor más bajo de absorbancia (0.011); no obstante, al aumentar el tiempo de exposición del tubérculo en agua con el inhibidor se observa un ligero ascenso de la absorbancia (a 0.134). Este compuesto es probablemente uno de los más ampliamente utilizado como agente antipardeamiento; además, por sus propiedades reductoras, disminuye ligeramente el $\mathrm{pH}$ teniendo un efecto directo en la PPO, ya que reduce las o-quinonas a o-difenoles (Science, Technology and Market, 2002).

Según Barrero y Sandoval (2006), el pH óptimo de las fenolasas cubre un rango entre 6 y 7, al reducir el $\mathrm{pH}$ por debajo de 3 la actividad enzimática se reduce notablemente. Sin embargo, en este estudio el ajuste del $\mathrm{pH}$ con un solo acidulante no evitó el oscurecimiento.

Con ácido cítrico (Línea F) se registró los más altos niveles de absorbancia en comparación a los expuestos anteriormente; sustentando la teoría que es necesario usar cítrico con combinaciones de otros tipos de agentes antipardiamiento (Science, Technology and Market, 2002). 
Por otro lado, la Fig. 1(b) muestra que a diferencia de la variedad Granola, la Provento presenta niveles de absorbancia mayores (superior a 0.20) aun cuando se tratara de inhibir la PPO mediante métodos físicos combinados con inhibidores enzimáticos. La línea A y B (sin tratamiento $\mathrm{y}$ sumergidas en agua, respectivamente) muestran un aumento gradual de la absorbancia en el tiempo, hasta llegar a un máximo (entre 0.78 y 0.80 ), observándose un decrecimiento de la absorbancia de la línea B a $40 \mathrm{~min}$.

La línea D representa el comportamiento de la absorbancia de la papa variedad Provento sometida a calor por un método de escaldado y enfriada en una solución de agua con metabisulfito de sodio a $5{ }^{\circ} \mathrm{C}$. Desde los 0 a 40 min se observa un descenso en los niveles de absorbancia (hasta 0.19, siendo éste el menor valor reportado), pero a los $60 \mathrm{~min}$ se incrementa gradualmente hasta llegar un valor de 0.28; situación contraria a la experimentada con la papa Granola donde hasta los $20 \mathrm{~min}$ bajan los niveles de absorbancia; no obstante, ambas tienen a estabilizarse a mayor tiempo se exposición.

La línea E y F representan las absorbancias de las papas Provento inhibidas con agentes reductores como el ácido cítrico y el ascórbico, en ambas se observa que a mayor tiempo de exposición (> $40 \mathrm{~min}$ ) estos pierden poder de inhibición enzimática como sucedió con la papa Granola, confirmándose el planteamiento teórico sobre las desventajas del uso de este tipo de inhibidores enzimáticos (Guerrero-Eraso, 2009).

Tomando en cuenta los resultados obtenidos para ambas variedades, bajo las condiciones establecidas, se puede decir que la actividad de la PPO depende mucho de la concentración de iones hidrógeno del medio y a cambios en los grados de ionización de los aminoácidos del sitio activo de la enzima, del sustrato, o bien del complejo enzima-sustrato porque ello determina la afinidad que tiene la enzima por el sustrato.

La diferencia en tiempos óptimos de inhibición enzimática, puede estar ligado a la variedad o tipos de papa. La papa de color amarillo posee un poco más de hidratos de carbono en su estructura como es el caso de la Provento; en consecuencia los sustratos son ionizables y se afecta el $\mathrm{pH}$ de los grupos iónicos de la enzima únicamente, facilitando un óptimo proceso de inhibición de la PPO. El pH tiene un efecto muy marcado en la estructura conformacional de los polipéctidicos, alterando la actividad de las enzimas (Hernández-Valdez, 2009).

\subsection{Curva de secado}

Para obtener las curvas de secado de la pasta de papa variedad Provento (P) y Granola (G), se usaron los siguientes métodos: (1) tratamiento de escaldado; (2) tratamiento térmico y uso de ácido ascórbico; (3) tratamiento térmico y uso de metabisulfito de sodio; y (4) cocción.

Para ello, la pasta se secó a una temperatura de $60{ }^{\circ} \mathrm{C}$ y una velocidad de aire de $0.2 \mathrm{~m} / \mathrm{s}$, anotando los datos de cambios de peso cada cierto intervalo de tiempo sin detener la operación de secado. Obteniendo como resultado 8 curvas de secado con cada método de inactivación para las dos variedades de papa en estudio, realizando una réplica para cada experimento. En total se obtuvieron 16 curvas de secado.

Con los resultados de los pesos registrados, se procedió a calcular el contenido de humedad a diferentes tiempos con la Ecuación (1). Con los datos obtenidos se graficaron las curvas de secado para ambas variedades con los diferentes tipos de tratamiento utilizados, las cuales se presentan en la Fig. 3 para la variedad Provento y en la Fig. 4 para la variedad Granola.

El comportamiento de secado de la pasta de papa, en todos los casos, fue decreciente, lo que indica que el secado transcurre con resistencia del sólido. En las curvas de secado mostradas en la Fig. 3 (Provento) y en la Fig. 4 (Granola), se puede observar la influencia del uso de los diferentes métodos de inactivación enzimática. De los métodos utilizados con tratamiento previo al secado del producto, se observó que se alcanzaba el peso constante de manera más rápida con la cocción; este comportamiento fue similar para ambas variedades de papa. Además, 
en las curvas obtenidas de velocidad de secado (ver Fig. 5) se puede notar que las mayores tasas de velocidad fueron obtenidas con el método de escaldado y cocción para el caso de la papa de variedad Provento; mientras que, para la papa variedad Granola, la mayor velocidad de secado fue cuando se utilizó ácido ascórbico, aunque cuando se llega a una humedad del 0.1 en base seca se observa un incremento de la velocidad de secado de la papa escaldada lo que permite que ésta se deshidrate más rápidamente. Con la aplicación de la cocción se destruyen las membranas celulares de la papa por el calor suministrado, lo que hace que el agua sea eliminada más rápidamente. En cambio, con el uso del metabisulfito de sodio sucede lo contrario, los sulfitos depositados en la superficie del sólido provocan la disminución de la velocidad de secado. Por otra parte, a pesar que el método de escaldado destruye parte de las membranas celulares de la papa y puede destruir las polifenoloxidasas, las cuales provocan el pardeamiento enzimático, puede producirse el fenómeno de regeneración el cual consiste en la recuperación de actividad transcurrido un tiempo después del tratamiento térmico (Hemeda y Klein, 1990). Aunque, el ácido ascórbico es uno de los más recomendado para prevenir el pardeamiento enzimático por reducción de compuestos quinónicos a sus compuestos polifenólicos originales (Walter, 1977), se logró verificar que no es recomendable su uso en el secado convectivo por aire caliente ya que el mismo se descompone dando productos coloreados.
Las curvas de secado obtenidas experimentalmente fueron modeladas utilizando el modelo de Midilli et al. (2002) modificado, asumiendo un valor de $n=1$ y agregado un tercer parámetro (el valor de $c$ ) para un mejor ajuste del modelo a los datos experimentales:

$$
M R=a \exp \left(-k t^{n}\right)+b t+c
$$

Para determinar el buen ajuste de los datos experimentales al modelo propuesto, se consideró el uso de tres parámetros estadísticos: El coeficiente de determinación $\left(\mathrm{R}^{2}\right)$, la suma de los cuadrados del error (SSE) y la raíz del error cuadrático medio (RMSE). El análisis estadístico y el ajuste del modelo a los datos experimentales fueron llevados a cabo usando el programa MatLab. En la Tabla 3 se muestran los parámetros del modelo de Midilli modificado y los valores estadístico de los datos ajustados al modelo, del secado de pasta de papa variedad Provento (P) y Granola (G) considerando los diferentes métodos de tratamiento. Los altos valores de $\mathrm{R}^{2}$ (> 0.99) y los bajos valores de SSE y RMSE en todos los casos, indican el buen ajuste del modelo propuesto por Midilli et al. (2002) a los datos experimentales (ver Figs. 3 y 4). Resultados similares fueron obtenidos por Taheri-Garavand et al. (2011) quienes aplicaron diferentes modelos para el secado de tomate, concluyendo que el modelo que mejor ajusta los datos experimentos fue el modelo de Midilli et al. (2002) ya que mejor describe el comportamiento del secado de tomate.

Tabla 3 Parámetros del modelo de Midilli modificado y valores estadístico de los datos ajustados al modelo, del secado de pasta de papa variedad Provento $(\mathrm{P})$ y Granola $(\mathrm{G})$ considerando diferentes métodos de tratamiento: (1) escaldado; (2) térmico + uso de ácido ascórbico; (3) térmico + uso de metabisulfito de sodio; y (4) cocción.

\begin{tabular}{c|c|c|c|c|c|c|c|c}
\hline $\begin{array}{c}\text { Parámetros } \\
\text { del modelo }\end{array}$ & $\mathrm{P} 1$ & $\mathrm{P} 2$ & $\mathrm{P} 3$ & $\mathrm{P} 4$ & $\mathrm{G} 1$ & $\mathrm{G} 2$ & $\mathrm{G} 3$ & $\mathrm{G} 4$ \\
\hline$a$ & 6.638 & 1.873 & 7.464 & 15.09 & 7.98 & 6.971 & 9.312 & 3.595 \\
\hline$b$ & 0.008558 & 0.001275 & 0.006478 & 0.01254 & 0.008155 & 0.006165 & 0.007253 & 0.003436 \\
\hline$c$ & -5.659 & -0.8666 & -6.402 & -14.09 & $-6,917$ & -5.956 & -8.3 & -2.608 \\
\hline$k$ & 0.002533 & 0.004048 & 0.001711 & 0.001265 & 0.00195 & 0.001721 & 0.00135 & 0.002613 \\
\hline $\mathrm{R}^{2}$ & 0.9998 & 0.9995 & 0.995 & 0.9999 & 0.9937 & 0.9996 & 0.9998 & 0.9996 \\
\hline SSE & 0.002366 & 0.00387 & 0.0405 & 0.000992 & 0.05409 & 0.003166 & 0.001588 & 0.00251 \\
\hline RMSE & 0.004334 & 0.007184 & 0.02477 & 0.003937 & 0.02885 & 0.006631 & 0.004798 & 0.006167 \\
\hline
\end{tabular}



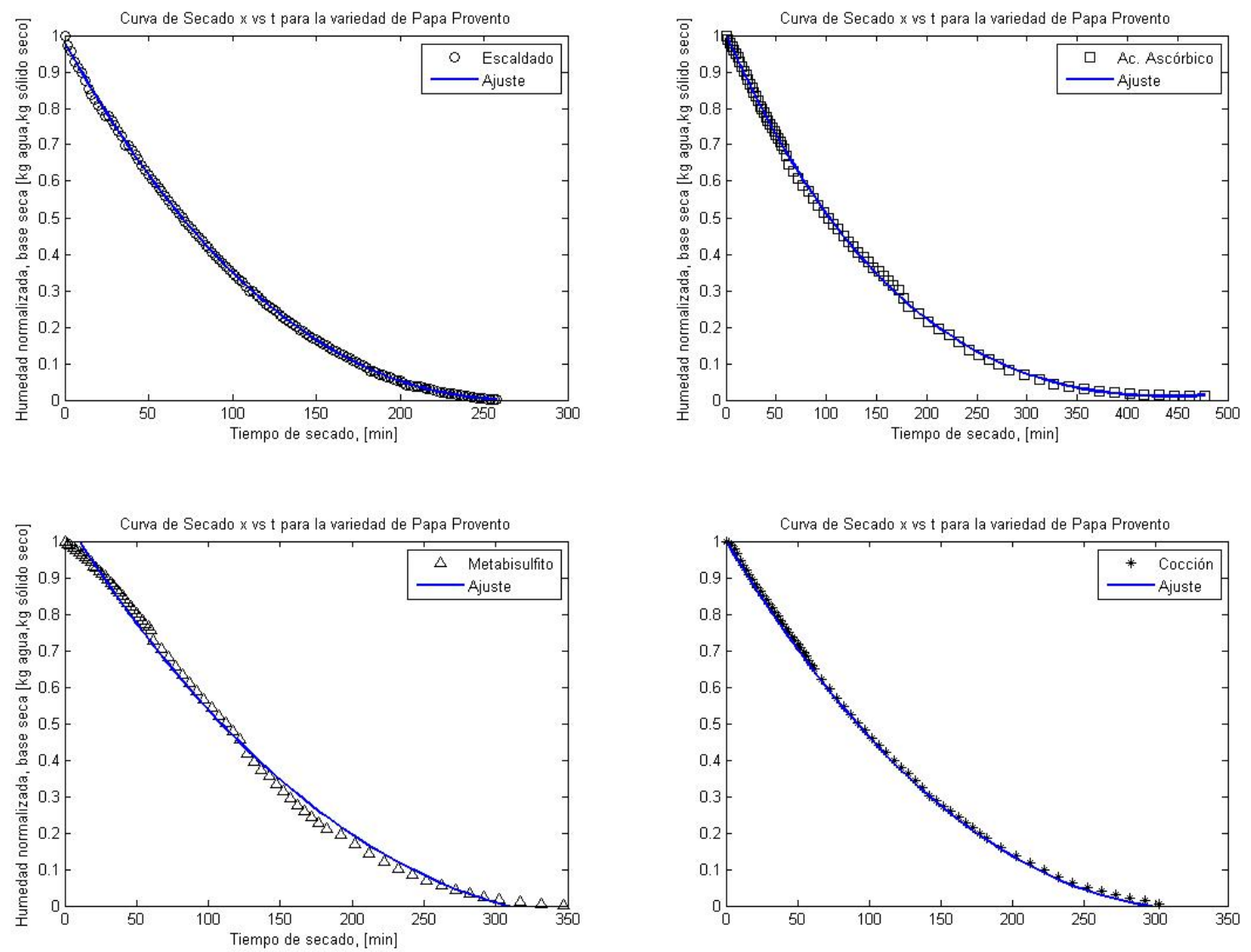

Fig. 3 Curva de secado de la pasta para harina de papa de la variedad Provento y ajuste de los datos experimentales al modelo de Midilli modificado, considerando diferentes métodos de tratamiento previo al proceso de secado.

\subsection{Producción de harina de papa}

En este proceso destacan las etapas de inhibición enzimática, reducción de tamaño y secado porque definen la calidad del producto y tiempo para obtenerlo.

En un primer método, la etapa de inhibición enzimática fue lograda con el escaldado rápido a $85{ }^{\circ} \mathrm{C}$, seguido de un enfriamiento en agua a 10 ${ }^{\circ} \mathrm{C}$ durante 40 minutos; sin embargo, al calentar se generó una inhibición ya que el almidón durante esa etapa capta más agua irreversiblemente y se hincha, generando la gelatinización. Durante el enfriamiento en agua, al haberse roto los puentes de hidrogeno entre las moléculas de almidón, el agua penetró más profundamente en el gránulo de almidón originando la gelificación (Vaclavik y Christian, 2002).
En la etapa de molienda, para que pudiera existir una reducción de tamaño se agregó agua, lo que incrementó la humedad y deterioro de la textura de la pasta de papa que fue introducida al secado. Con este primer método las variedades Provento y Granola aumentaron un 10\% y 13\% de humedad, respectivamente. Producto de ello ocurre una saturación de líquido en la membrana celular del tubérculo, retención de agua en ciertas partes, secado no uniforme de la pasta; así como la aparición de pigmentaciones en la harina obtenida después de más de 20 horas de secado.

Tomando en cuenta los resultados anteriores, se procedió a realizar un segundo método de inhibición enzimática y reducción de tamaño con la finalidad de obtener una harina de mejor calidad en menor tiempo. 
Alonso et al.
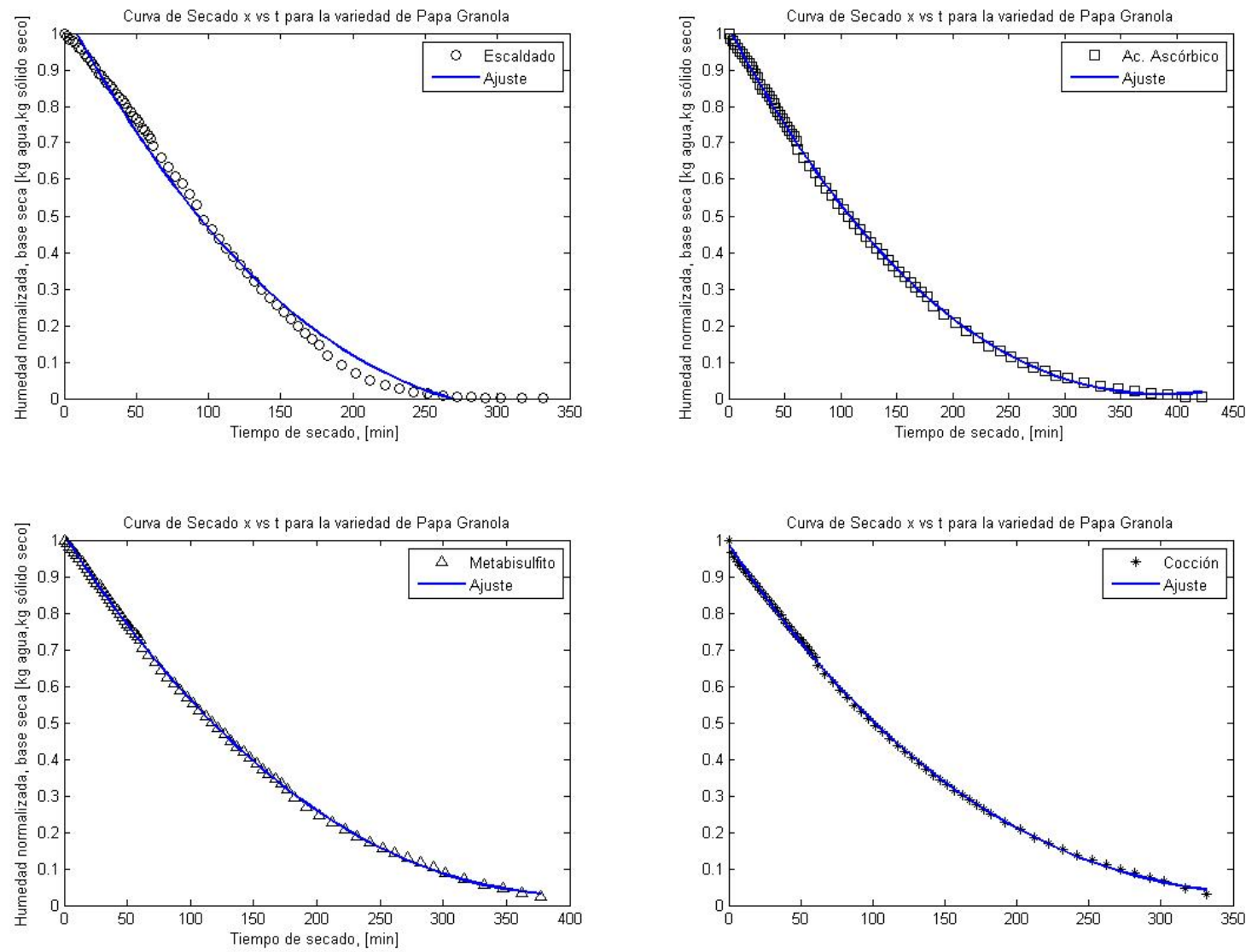

Fig. 4 Curva de secado de la pasta para harina de papa de la variedad Granola y ajuste de los datos experimentales al modelo de Midilli modificado, considerando diferentes métodos de tratamiento previo al proceso de secado.

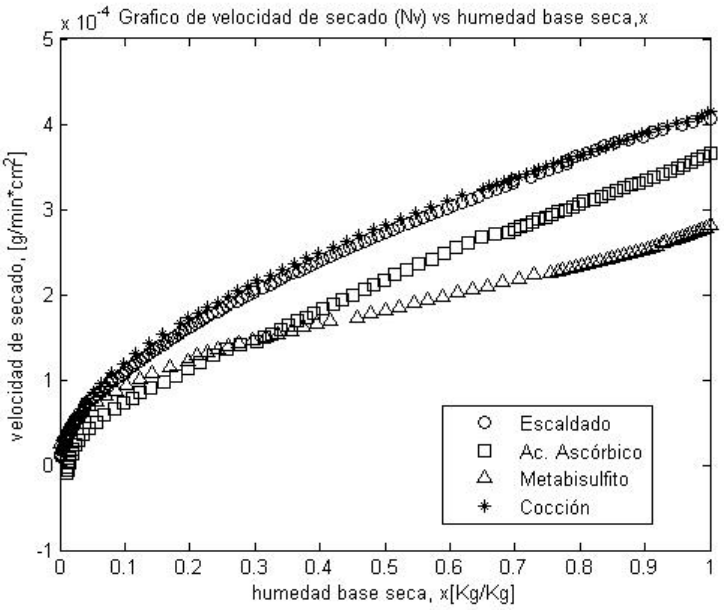

(a) Papa variedad Provento

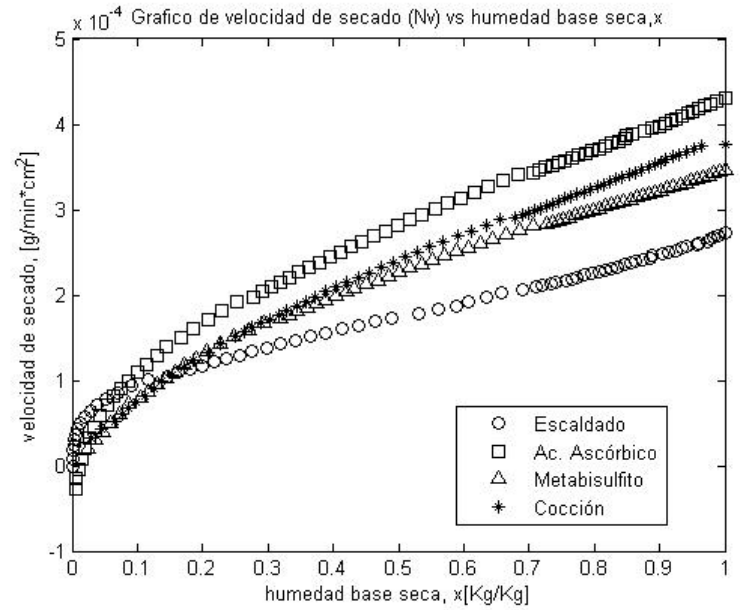

(b) Papa variedad Granola

Fig. 5 Curva de velocidad de secado de la pasta para harina de papa de (a) vairedad Provento y (b) variedad Granola, considerando diferentes métodos de tratamiento previo al proceso de secado. 
Para inhibir la enzima se aplicó cocción a una temperatura de $90-95{ }^{\circ} \mathrm{C}$ durante $20 \mathrm{~min}$. El enfriamiento de los cubos de papa se realizó a temperatura ambiente sin ser afectados por el oxígeno atmosférico. La enzima se inhibió casi en su totalidad, a los 80 min (tiempo máximo de enfriamiento) alcanzando un valor de absorbancia de 0.061 (Granola), aunque se recomienda enfriar las papas durante $10 \mathrm{~min}$.

Con el tiempo de enfriamiento se debe tener mucho cuidado ya que si los cubos de papa están muy fríos al momento de la maceración, la gelificación del almidón deteriora la consistencia de la pasta ocasionando un mayor tiempo de secado. Por otra parte, para la reducción de tamaño se realizó una maceración con mortero, las papas fueron aplastadas sin usar agua hasta alcanzar consistencia de puré, siendo vertido en un pírex de acero inoxidable formando una torta de un grosor no superior a $3 \mathrm{~mm}$.

Con el desarrollo de ambos métodos se comprobó que al estar caliente la membrana celular de la papa se hincha por la gelatinización del almidón, por ende el no usar los niveles de humedad de la pasta introducida al horno disminuye en comparación al primer método descrito, logrando menores tiempos de secado. Para ambas variedades, el tiempo promedio de secado de $255 \mathrm{~g}$ de papa fue de 18 horas aproximadamente, obteniéndose hojuelas con una humedad del $3.91 \%$ en la papa variedad Provento y $4.3 \%$ en la papa variedad Granola, siendo aún menores que los contemplados por la FAO, que consideran entre 5 y $8 \%$ de humedad para la harina (FAO, 2008).

\subsection{Rendimiento en la elaboración de harina de papa}

Este rendimiento fue calculado para las dos variedades de papa en base húmeda y base seca. El rendimiento en base húmeda se calculó dividiendo el peso de harina obtenida entre el peso de papa íntegra; mientras que el rendimiento en base seca se calculó como el cociente del peso de harina obtenida entre el contenido de materia seca de la papa. El análisis se aplicó a tres ensayos realizados para cada variedad, los resultados se muestran en la Tabla
4. Teóricamente se sabe que la papa está conformada de un $72-78 \%$ de agua, $16-20 \%$ de fécula en forma de almidón, 2-2.5\% de sustancias nitrogenadas, $0.15 \%$ lípidos y $1-1.8 \%$ de fibra dietética como celulosa. Las variedades de papas nacionales, contienen una mayor cantidad de agua (superior a los 80\%) en su estructura, influyendo directamente en los rendimientos de obtención de harina.

Según los resultados plasmados en la Tabla 4, no existe una marcada diferencia entre la obtención de harina usando Granola y Provento; en promedio, la Granola posee un $13.15 \%$ y la Provento $13.81 \%$ de rendimiento en base húmeda.

En los resultados de rendimiento en base seca existe una ligera diferencia, la papa variedad Granola obtuvo un $58.48 \%$ y la papa variedad Provento $56.53 \%$. Esta diferencia del $1.95 \%$ es producto de que la papa Granola posee mayor contenido de materia seca en comparación a la papa Provento, lo que incide en un mayor rendimiento.

Cabe mencionar que los resultados de la obtención de harina no solamente están en dependencia del contenido de agua y materia seca que posee cada papa; las etapas de recepción, pelado y corte, reducción de tamaño y secado influyen también en este resultado. Si el abastecedor del tubérculo no proporciona papas de buena calidad, en la etapa de pelado y corte se tendría que eliminar partes malas, lo cual aumenta la generación de residuos y disminuye la cantidad de puré de papa cocida que entraría a la etapa de secado. Además, en la etapa de pelado entra en juego la experiencia y humor de la persona que lleva a cabo dicha acción así como también el instrumento con que lo realiza. Se recomienda que se ejecute con peladores de papas manuales o eléctricos y no con cuchillos, porque con ellos se desprende parte del tejido vegetal que interesa. La reducción de tamaño es mejor realizarla en una superficie lisa que permita desprender el puré gelatinizado, evitando que queden residuos.

El horno es también importante. En este estudio se utilizó uno de bandejas que realiza un secado 
estacionario, algunas partes de las hojuelas presentaban reacción de Maillard ya que los azúcares de las papas se someten más tiempo a calor al existir partes humedecidas, producto del secado no uniforme. Esto causa que esas partes humedecidas del producto que no cumplen con las características establecidas, se rechazara.

Tabla 4 Rendimiento de los ensayos de elaboración de harina de papa.

\begin{tabular}{|c|c|c|c|c|c|c|c|c|}
\hline \multirow{3}{*}{ Etapas } & \multicolumn{8}{|c|}{ Variedades } \\
\hline & \multicolumn{4}{|c|}{ Granola } & \multicolumn{4}{|c|}{ Provento } \\
\hline & No.1 & No. 2 & No.3 & Prom. & No.1 & No. 2 & No.3 & Prom. \\
\hline $\begin{array}{l}\text { Rendimiento base } \\
\text { húmedo }(\%)\end{array}$ & 12.55 & 12.81 & 14.09 & 13.15 & 14.69 & 11.18 & 15.58 & 13.82 \\
\hline $\begin{array}{l}\text { Rendimiento base } \\
\text { seca }(\%)\end{array}$ & 62.69 & 53.69 & 59.05 & 58.48 & 51.02 & 49.53 & 69.03 & 56.53 \\
\hline
\end{tabular}

\subsection{Análisis fisicoquímico de la harina de papa}

El producto obtenido de la elaboración de harina de papa (variedades Provento y Granola), utilizando la segunda metodología de inhibición enzimática y reducción de tamaño, fue sometido a diferentes análisis fisicoquímicos: contenido de agua, contenido de cenizas, contenido de proteínas, porcentaje de fibra, contenido de carbohidratos, aporte energético, índice de solubilidad en agua (ISA), índice de adsorción en agua (IAA) y el poder de hinchamiento (PH).

Los resultados mostraron que la cantidad de agua contenida en las muestras de harina de la variedad de papa Provento osciló entre 3.704.06\%; por su parte la variedad Granola tuvo entre $4.10-4.50 \%$ de humedad. Estos datos se encuentran por debajo de los establecidos en documentación de la FAO que oscilan entre 5$8 \%$ para harina de papa. El contenido de cenizas presente en ambas harinas arrojó que la presencia de minerales es equilibrada. La variedad Provento tuvo el resultado más alto, una media del $3.35 \%$ y la Granola $2.84 \%$. No existe ningún dato de ceniza en harina de papa nacional; sin embargo, en pruebas realizadas en América del Sur se estima que la harina con papa criolla (amarilla) es de aproximadamente $3.20 \%$ (Escobar y Varela, 2008), similar a los resultados obtenidos en este estudio.

La harina que tiene mayor cantidad de proteínas fue la variedad Granola con un $0.0474 \%$, en cambio la Provento alcanzó el $0.0380 \%$. Estos resultados son muy bajos en comparación a los estudios realizados en América del Sur sobre la harina de papa criolla que ronda los $6 \%$ de contenido proteico (Escobar y Varela, 2008).

El contenido de grasa cruda presente en la harina de la variedad Granola fue de $0.60 \%$, similar a la Provento que alcanzó el $0.53 \%$. Según la Comisión Veracruzana de Comercialización Agropecuaria, la papa seca presenta $0.4 \%$ de grasa, similar a los resultados obtenidos. Esto genera una característica positiva del producto, los valores bajos de grasa inciden en la no rancidez de la harina una vez envasada. Por otro lado, el porcentaje de fibra en ambas harinas es similar, la Granola obtuvo $2.36 \%$ y la Provento $2.18 \%$, muy por debajo a la referencia mexicana que estima los $8.4 \%$.

La importancia de la papa radica en su versatilidad culinaria y su alto contenido de carbohidrato, convirtiéndola en un generador de energía básica en la alimentación. De las dos variedades la que posee mayor contenido de carbohidratos es la harina con papa Provento con un $93.03 \%$; la Granola también posee una buena cantidad de carbohidratos en su estructura nutricional con un $92.56 \%$. Estos valores se encuentran muy por encima de los estudios en América del Sur sobre la harina de papa criolla que ronda los 73.13\% (Escobar y Varela, 2008)

En cuanto al aporte energético tampoco existen muchas diferencias; por cada 100 gramos de harina con papa Provento se tienen 372.294 kcal 
y con la Granola $370.45 \mathrm{kcal}$; estos valores justifican la importancia de la papa como buena fuente de calorías, convirtiéndolas en un alimento fundamental para muchas personas; sin embargo, es necesario equilibrar la dieta con presencia de otras hortalizas y con alimentos de cereales integrales.

Se consideró importante el análisis de adsorción de agua y las características de solubilidad porque la morfología, el procesamiento y la composición de las harinas afectan sus propiedades funcionales. Para la harina de ambas variedades se determinó, por duplicado, el índice de solubilidad en agua (ISA), índice de adsorción en agua (IAA) y el poder de hinchamiento $(\mathrm{PH})$. Los resultados se presentan en la Tabla 5.

Los resultados a los $25{ }^{\circ} \mathrm{C}$ demuestran que no existen diferencias significativas en el punto de hinchamiento, adsorción de agua y solubilidad en agua. Esto puede deberse a que en ambas variedades existe el mismo grado de modificación de los almidones a esa temperatura, a pesar de los tratamientos termomecánicos aplicados (Sandoval et al., 2006).

Tabla 5 ISA (\%), IAA y PH de las harinas a una temperatura de $25{ }^{\circ} \mathrm{C}$ y $90{ }^{\circ} \mathrm{C}$.

\begin{tabular}{c|c|c|c|c}
\hline \multirow{2}{*}{ Indicadores } & \multicolumn{4}{|c}{ Variedades } \\
\cline { 2 - 5 } & \multicolumn{2}{|c|}{ Granola } & \multicolumn{2}{c}{ Provento } \\
\cline { 2 - 5 } & $25^{\circ} \mathrm{C}$ & $90^{\circ} \mathrm{C}$ & $25^{\circ} \mathrm{C}$ & $90^{\circ} \mathrm{C}$ \\
\hline $\begin{array}{c}\text { ISA } \\
(\%)\end{array}$ & 0.32 & 21.84 & 0.50 & 22.37 \\
\hline IAA & 12.39 & 13.32 & 10.08 & 5.67 \\
\hline PH & 12.43 & 17.04 & 10.14 & 7.80 \\
\hline
\end{tabular}

La harina de papa tiene una gran cantidad de almidones en su estructura y con los resultados de IAA y PH, se puede decir que alcanzó la característica de almidón instantáneo porque logra hincharse sin aplicación de calor; sin embargo, requiere más tiempo y mayor contenido de harina para espesar por la rotura del granulo de almidón durante la gelatinización y el secado (Vaclavik y Christian, 2002).
A los $90{ }^{\circ} \mathrm{C}$ la Granola alcanza los máximos valores de $\mathrm{pH}$ producto de la gelatinización del almidón; contrario a lo sucedido en la Provento, la cual baja su poder de hinchamiento. La solubilidad y la absorción de agua son parámetros que muestran la magnitud de la interacción entre las cadenas de almidón dentro de las secciones amorfas y cristalinas que la conforman; el IAA en la papa Granola es mayor que en la Provento, en cambio el ISA es similar en ambas variedades (Sandoval et al., 2012).

El mayor poder de hinchamiento y absorción de la variedad Granola, se debe, probablemente, al alto contenido de grupos fosfato en la amilopectina contenida en ella, los cuales generan una repulsión en las cadenas adyacentes, incrementando la hidratación por el debilitamiento de los enlaces dentro de la parte cristalina del gránulo (Sandoval et al., 2012).

\section{Conclusiones}

Las papas nacionales que se estudiaron (Provento y Granola) superan el contenido de humedad que estipula la FAO para la elaboración de harina, con un 8 a $11 \%$ más de agua en comparación a la referencia.

Los tratamientos fisicoquímicos y aplicados para inhibir la Polifenoloxidasa (PPO) presente en las variedades de papa fueron efectivos, logrando disminuir considerablemente la oxidación o la formación de quinonas con relativa facilidad. Aunque, para lograr la inactivación total no es suficiente el escaldado, se precisa una cocción a altas temperaturas y a mayor tiempo.

Con las curvas de secado se demostró la importancia de aplicar a la papa tratamientos térmicos y/o inhibidores enzimáticos previa al secado. Influyendo en los tiempos de deshidratación, reactivación de la enzima, calidad y costos de obtención de harina. El mejor método para elaborar harina de papa y con el cual no se reactivaría la PPO es con la cocción completa del tubérculo antes de su deshidratación. El modelo Midilli modificado describió satisfactoriamente los datos experimentales del proceso de secado. En el proceso desarrollado para obtener harina de papa 
destacan las etapas de inhibición enzimática por cocción a $90{ }^{\circ} \mathrm{C}$ durante 20 minutos, reducción de tamaño en seco mediante una maceración y secado por contacto a $60{ }^{\circ} \mathrm{C}$ por 18 horas en un horno de bandejas.

Con la papa Granola y Provento el rendimiento de producción de harina es similar, en base húmeda tuvieron $13.15 \%$ y $13.81 \%$ respectivamente. La variedad Granola posee el menor contenido de humedad destacando por su mejor rendimiento en base seca con el $58.48 \%$. Sin embargo, estos valores podrían mejorar si el proceso de elaboración de harina fuera automatizado. Las harinas producidas con las papas variedad Granola y Provento lograron un nivel de humedad más bajo que la referencia internacional, $3.70-4.06 \%$ y $4.10-4.50 \%$ de humedad, respectivamente, favoreciendo la vida útil del producto. Los valores alcanzados en los análisis físicos químicos resaltan la importancia nutricional de la papa destacando su equilibrado contenido de cenizas (minerales), fibra y alta presencia de carbohidratos. La variedad Granola posee un almidón rico en amilosa por su alto poder de hinchamiento y de producción de gel. En cambio la variedad Provento espesa pero no gelifica por contener un almidón con alto porcentaje de amilo-pectina. El almidón de las harinas producidas con ambas variedades tuvo la particularidad de hincharse en presencia de agua a $25{ }^{\circ} \mathrm{C}$, considerándose un almidón instantáneo que ofrece comodidad, estabilidad, claridad y textura siendo óptima para realizar puré instantáneo.

\section{Agradecimientos}

Los autores agradecen a la FAO, Universidad Nacional de Ingeniería (UNI), Facultad de Ingeniería Química (FIQ), Programa de Investigación en Ing. de Procesos y Ambiental, SERFIQ-CETEAL, por el apoyo suministrado para la realización y publicación de este trabajo.

\section{Referencias}

Barreiro, J., Sandoval, A. (2006). Operaciones de conservación de alimentos por bajas temperaturas. Edo. Miranda: Equinoccio, Universidad de Venezuela.
Egúsquiza, B. (2000). La Papa: producción, transformación, comercialización. Lima: CIMAGRAF S.R.L.

Escobar, A., Varela, J.C. (2008). Aprovechamiento de la harina de papa criolla (solanumphureja) como sustituto parcial de la sémola de trigo en la formulación y elaboración de una pasta alimenticia tipo spaghetti. Universidad de la Salle, Bogotá, Colombia.

FAO (2008). Año Internacional de la papa. Revisado el 24 de abril 2013 desde Internet. En línea: http://www.fao.org/potato-2008/es/

FAO (2010). Fortalecimiento de la Seguridad Alimentaria, con énfasis en el incremento de la disponibilidad de alimentos generados en las cadenas agroalimentarias del rubro alimenticio de la papa y del maíz en Nicaragua. Revisado el 24 de abril 2013 desde Internet. En línea:

http://coin.fao.org/cms/world/nicaragua/es/Forta lecimiento_Papa_y_Maiz.html

Gallegos, A., Umaña, B. (2011). Elaboración de harina de papa. Tesina para optar al título de Ingeniero Químico, Universidad Nacional de Ingeniería, Managua, Nicaragua.

Guerrero-Eraso, C.A. (2009) Inhibición de la actividad enzimática de la polifenol oxidasa extraída del banano (cavendish valery) mediante sistemas bifásicos acuosos con isoespintanol y ácido ascórbico. Tesis de Maestría, Universidad Nacional de Colombia, Sede Medellín.

Hemeda, H., Klein, B. (1990). Inactivation and Regenaration of Peroxidase Activity in Vegetable Extracs Treaded with Antioxidants. J. Food Sci. 56(1): 68-71.

Hernández-Valdez, C.E. (2009). Acción y efectos de la polifenoloxidasa en alimentos. Tesis para optar al Grado de Ingeniero Industrial. Universidad Veracruzana, Facultad de Ciencias Químicas.

Kirk R.S., Sawyer R., Egan, H. (1996) Composición y análisis de alimentos de Pearson, segunda edición; Compañía editorial continental SA de CV, México. 
Midilli, A., Kucuk, H., Yapar, Z. (2002) A new model for single layer drying. Dry Technology 120 (7): 1503-1513.

Science, Technology and Market (2002). Control de Pardeamiento Enzimático. Revisado Agosto 2014 desde Internet:

http://aromateca.com/main/index2.php?option=c om_content\&do_pdf $=1 \& i d=80$

Sandoval, A.L., Sandoval, G. (2012). Influencia de la sustitución parcial de la harina de trigo por harina de quínoa y papa en las propiedades termomecánicas y de panificación de masas. Revista U.D.C.A Actualidad \& Divulgación, 15(1): 199-207.

Sandoval, E., Fernández-Quintero, A., Alcalá, L.A., Ospina-Pati, B. (2006). Reología de suspensiones preparadas con harina precocida de yuca. Ingeniería y Desarrollo 19(1): 17-30.
UNAD (2008). Lección 38: Pardeamiento enzimático. Universidad Nacional abierta y a distancia. Revisado el 24 de abril 2013 desde Internet. En línea: http://datateca.unad.edu.co/contenidos/202015/2 02015/leccin_38_pardeamiento_enzimatico.html

Taheri-Garavanda, A., Rafieea, S., Keyhania, A. (2011). Mathematical Modeling of Thin Layer Drying Kinetics of Tomato Influence of Air Dryer Conditions. International Transaction Journal of Engineering, Management, \& Applied Sciences \& Technologies 2(1): 147-160.

Walter J.R.L. (1977). Enzimatic browning in foods, its chemistry and control. Food Technology in New Zealand 12(1): 19-25.

Wikipedia (2014). Tampón Fosfato Salino. Revisado Agosto 2014 desde Internet: http://es.wikipedia.org/wiki/Buffer_fosfato_salino 